\title{
Nonverbal Communication in German-Albanian Cultural Contrast
}

Brikena KADZADEJ ${ }^{*}$

\begin{abstract}
This article explores the nonverbal communication by comparing the cultural features of Albanian (in Albania and Kosovo) and German cultures; also comparing the inter-cultural features in Albania and Kosovo, respectively. The human communication is beyond language: nonverbal communication includes all kinds of human behavior that are not strictly linguistic but convey meaning, i.e., a set of behaviors (e.g., gestures) with a specific referential value and a function. We focus on seven of the most important channels of nonverbal communication in a contrastive Albanian-German perspective: proxemics, eye contact, facial expressions, body language, touching, physical appearance, the extra-linguistic field. The field of nonverbal communication is often considered inferior in relation to verbal communication (comprised of language habits, grammar, lexicon, etc.). Although communication between members of two different cultures requires the knowledge of a foreign language, their communication actually begins before any words are uttered.
\end{abstract}

Keywords: Nonverbal Communication, extra-linguistic, Albanian, German, culture

\footnotetext{
* Orcid id: https://orcid.org/0000-0001-6293-5299, Prof. Dr., University of Tirana. Faculty of Foreign Languages, Department of German Language, bkadzadej@hotmail.com

${ }^{* *}$ (Corresponding author) Orcid id: https://orcid.org/0000-0003-2916-516X, Prof. Ass. Dr., University of Prishtina "Hasan Prishtina", Faculty of Philology, Department of German Language and Literature, vjosa.hamiti@uni-pr.edu
} 


\section{INTRODUCTION}

In every culture, in addition to the biological conditions, interpersonal relationships are based on language, religion and tradition. Verbal communication of information is supplemented in all these areas visually and emotionally. In the course of communication/conversation, gestures, facial expressions, posture and intonation are often more meaningful than the spoken word itself. A wave of the hand, a smile, a shake of the head or a nod, a sigh or a pause in speech can influence the meaning of an utterance regardless of the sense of the word.

This research article examines aspects of nonverbal communication by comparing the cultural features of Albanian (in Albania and Kosovo) and German cultures. The field of nonverbal communication is often considered inferior in relation to verbal communication (comprised of language habits, grammar, lexicon, etc.). Although communication between members of two different cultures requires the knowledge of a foreign language, their communication actually begins before any words are uttered. (for more see Andersen et al., 2002)

"One cannot not communicate" is Paul Watzlawick's most famous maxim. This maxim postulates that communication does not necessarily require words, but that it also involves other means or dimensions. Since even silence can function as a means of communication, in this context there is a difference between active and non-active skills of communication (see Oksaar, 1988, p.26).

Communication is a multimodal phenomenon that goes beyond verbal language itself with its grammatical norms and systems. Some aspects of the outside environment can also say something about a person, their personality and their culture. These aspects are part of the so-called non-verbal communication, which plays a significant role in every kind of interaction. The non-verbal signs can serve to generate and support an interaction by completing, emphasizing and even replacing, denying or questioniong the verbal messages. When strangers meet, the attitude that determines the ensuing course of their relationship is formed even before any of the persons has spoken the first word.

Nonverbal communication conveys information about identity, culture, emotions and relationships. According to Ting - Toomey (1999, p.116) nonverbal communication serves:

1. reflecting and managing identities;

2. expressing emotions and attitudes;

3. conversational management;

4. impression formation and attraction. (for more see Ting - Toomey, 1999)

A language consists of visible or audible signs. Scholars share nonverbal communication in different groups. According to Ting - Toomey (1999: 116) the following forms form the nonverbal communication: 
- Kinesics (facial and bodily movements);

- Oculesics (eye contact);

- Vocalics/Paralinquistics (e.g., tone of voice, volume);

- Proxemics (spatial distance);

- Haptics (touch);

- Environment (e.g. decor, architecture) ;

- Chronemics (time). (for more see Ting - Toomey, 1999)

According to some other scholars (Hall, 1959, 1976, 1983; Han, 2004; Erll \& Gymnich, 2007; Knapp \& Hall, 2002; Richmond \& McCroskey, 2004) the nonverbal communication comprises:

- Gestures;

- Facial expressions;

- Eye contact;

- Body language, posture;

- External appearance (clothing, hairstyle);

- Symbolism, e.g. pictograms, use of colours, tattoos.

However, it must be stressed that the paralinguistic aspects and body language are the focus of verbal and nonverbal communication.

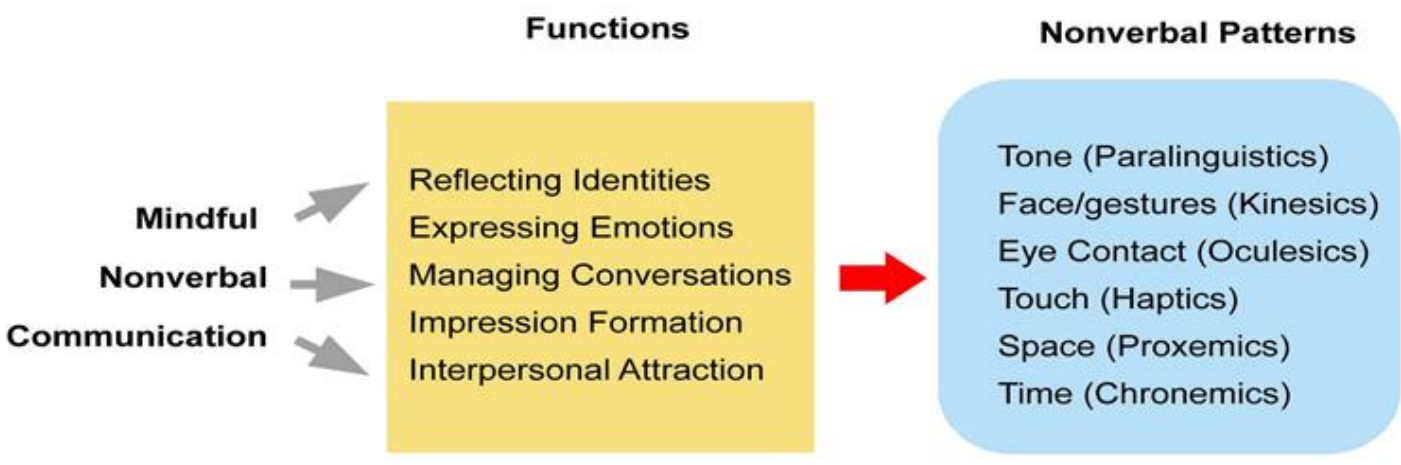

Figure 1. Mindful nonverbal communication: Functions and patterns according to Ting Toomey (1999, p.116) 
Successful communication, even within the same cultural circle and the same linguistic community, such as in Albania and Albanian-speaking Kosovo, encounters obstacles. Successful communication between members of two different cultural circles poses even more challenges, since in the vast majority of cases interlocutors cannot avoid the customs which shaped their personality. Therefore, chances for miscommunication between members of two different cultures and linguistic communities are higher.

Resistance to interacting with members of other cultures, or even discriminatory behavior towards them, is related to the lack of knowledge of other people's way of life, their living circumstances, their traditions and rites. Thus prejudices stem from ignorance.

„Die nonverbalen Signale bringen in sich somit ein interkulturelles Kommunikationspotential. Der nonverbale Bereich zwischenmenschlicher Interaktion weist einen zwiespältigen Charakter auf. Zum einen unterstützen nonverbale und paraverbale Signale eine Person beim Sprechen. Zum anderen können nonverbale Codes eigenständig als Bedeutungsträger fungieren" (Erll/Gymnich, 2007, p.110) ${ }^{1}$

We know and can understand our own culture better by encountering and being familiar with other cultures and then by communicating and reacting in a more competent way, and interculturally, with people from different cultures. Some researchers (e.g., Hall 1959; Vargas 1986) identify speakers of high-contact cultures, such as Arabs, Latin Americans, Greeks, Turks, the French, and Italians, who usually keep small distances among themselves; and low-contact cultures who "stand further apart," like the Chinese, Japanese, Thai, Germans. There has been no research on the Albanian contact culture visà-vis the German contact culture, although the two nations have engaged with oneanother for a couple of centuries.

German-language and Albanian-language speaking areas (primarily in Kosovo) have their own characteristic habits, cultures and communication rules. Thus, it is important to recognize these features and idiosyncrasies in order to avoid miscommunication and rejection by the other culture.

\section{METHOD}

For this article, we have drawn on literature in the field of nonverbal communication. However, highly important for this study has been the sharing of experiences with our own colleagues, as well as our own personal observations on the matter at hand for a number of years. Occasionally, we will make use of examples from the Albanian oral folk

\footnotetext{
${ }^{1}$ Our translation: Nonverbal signals are accompanied by a potential of intercultural communication. The nonverbal field of interaction between people has two sides. On the one hand, nonverbal and paralinguistic signals support a person in his/her speech, and on the other hand, nonverbal codes can themselves carry meaning (Erll \& Gymnich, 2007, p.110).
} 
tradition, which continues to be an important part of the Albanian national legacy in the present time.

This article discusses seven of the most important channels of nonverbal communication in a contrastive Albanian-German perspective:

1. Proxemics,

2. Eye contact,

3. Facial expressions,

4. Body language,

5. Touching,

6. Physical appearance,

7. The extralinguistic field.

These aspects will, in addition, be compared and contrasted in the Kosovan-Albanian perspective.

\section{FINDINGS}

\section{Proxemics}

The term 'proxemics' was coined by Edward T. Hall, and defined as "the study of how individuals unconsciously structure micro space - the distance between men in daily life, the organization of space in houses, buildings and ultimately a layout of towns." Hall began the study of proxemics by using systematic observations when it became apparent that people from different cultures interacting with each other do not always attach identical meaning to the same or similar measured distances. (Hall, 1963).

Proxemics deals with a distinct aspect of body language, namely the personal spatial relations between interlocutors. Some of the most important factors of nonverbal communication are the direction of one's body, height, distance, and touch. The central theme is "the social and personal space and how one perceives it". (Hall, 1976, p.15) 


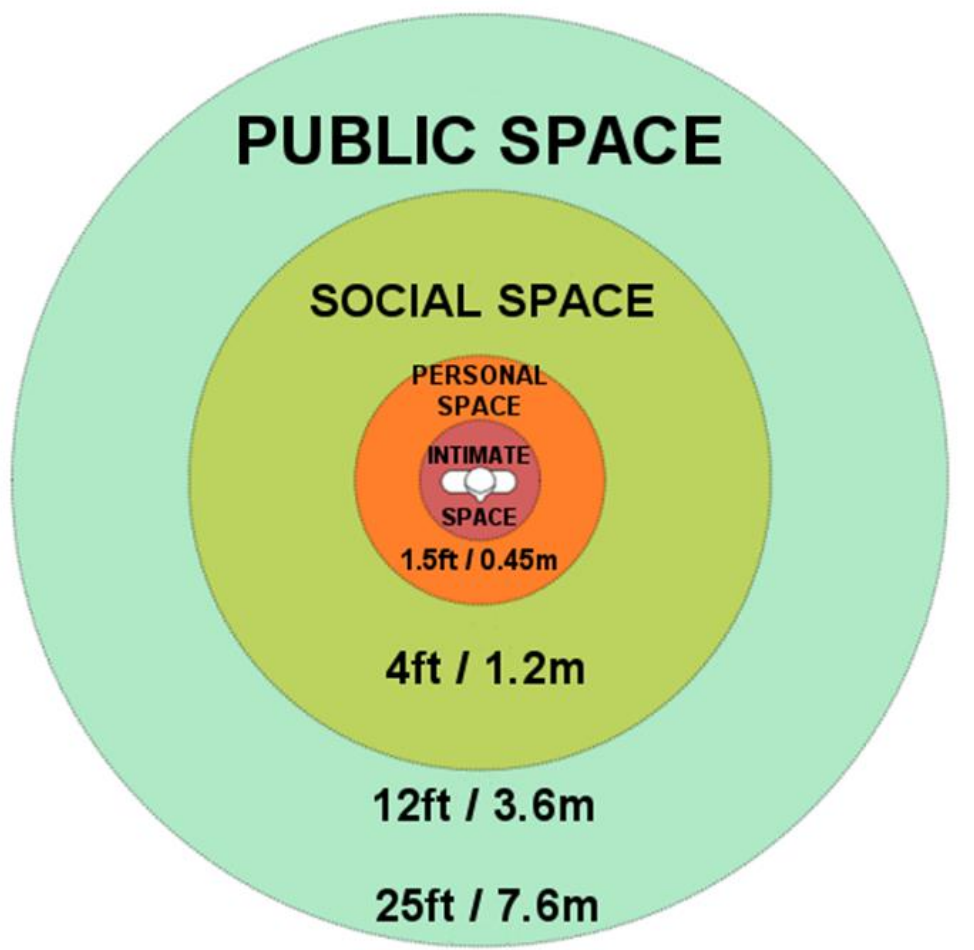

Figure 2. Representation of Edward Hall's reaction bubbles (WEB1)

Everyone of us has got what is known as an informal space. How one views informal space does not depend only on particular situations of communication, but also on cultural, gender, and professional features that belong to the people involved in the communication. Introverted and extroverted tendencies are other impacting features. Sommer defined personal space "an area with invisible boundaries surrounding a person's body into which intruders may not come" (Sommer, 1979, p.26). Though Sommer sees individual distance and personal space as closely related, he says that "individual distance may be outside the area of personal space" (1979, p.27).

In terms of how people view spatial relations, there are significant cultural differences when the behavior of two Germans is compared to that of two Albanians. It can often be observed that German interlocutors face each other at an arm's length distance between them, that is, not as close as the Albanian speakers tend to get to each other in a similar situation. This can be a source of misinterpretation, since Germans do not want to see other people approach them physically too close.

In both Albania and Kosovo it is considered normal if someone 'violates' another person's personal space. The short physical distance one keeps with his/her interlocutor is interpreted as 'interpersonal closeness' and 'more attention' (paid to the other). If there are problems in communication between Albanian interlocutors, physical distance between them varies. 
The short distance is required when one first meets his/her friends (be it compatriots or foreigners) outside (on the street, for instance). When the friend keeps a distance, the other person notes it verbally with expressions such as 'i tregon dhëmbët' ('show one's own teeth to someone' (an expression of aggression), 'nëse ka ndonjë gjë kundër tij' ('if there's something against the other person'), or 'nuk mund ta durojë atë' ('I can't bear him/her'), 'Pse rri larg?'('why are you so detached?'), 'Qasu!' ('come closer!'), 'Nuk të ha!' ('I am not going to eat you up'), etc.

From our own experience, we can say that the personal space is often determined by one's educational background, his/her traditions and culture.

\section{Touching}

Touching is a kind of perception that is realized through one's hand, fingers or other parts of the body. Touching is a significant element of communication. One of the people involved in communication manages to convey feelings of gratitude, safety, personal feelings, or support through touching his/her interlocutor.

However, touching is not always considered appropriate, and very often it is not acceptable. Many people do not like to be touched and this can lead to misunderstanding. Therefore, for a successful communication it is important to know how much touching (if any at all) is appropriate and how it is determined by the context, the individual, or the culture. Therefore, as discussed above, physical contact is not always appropriate.

The manifestation of this aspect of nonverbal communication depends on the relationship between the two people engaged in communication, the status of the initiator and the receiver of the physical contact. Other factors are important as well, such as age, gender, religion, and cultural identity.

According to Argyle, "the most basic meaning of touch is that an interpersonal bond is being offered or established" (Argyle, 1988, p.226). While touch can be used for consolation, support, and congratulations depending on the relationship, touch is often culturally regulated in organizations (Harris, 2002), meaning it may be regulated to behaviors such as handshakes. Touch, like any other communication message, may elicit negative and positive reactions depending on the configuration of people and the circumstances in which it occurs (Knapp \& Hall, 2002).

Traditionally, in the north of Albania and mountainous regions of Kosovo, where houses are located far from one other, physical contact is present in the very first meeting - one person places his/her hands on top of the interlocutor's hands (even if there are more people present around). In comparison with Germany, touching someone while conversing is considered very normal in this part of the Albanian-speaking world.

Albanians get quite close when they converse, and for them it is normal to touch one another inadvertently while they are walking and talking. Very often this is done to attract the interlocutor's attention and express feelings of friendship towards him/her. 
It is also considered normal to pat someone on the back. This can be done after greeting someone with both hands - when you grab a person's hand - as well as when you wish someone goodbye as a signal of a healthy friendship. These methods of greeting a close person are present today among both men and women. Among German men (who are related to one another), usually the right hands are shaken while the left hand is placed on the other person's shoulder. Different from a German-speaking environment, in both Albania and Kosovo, when someone is patted on the back it assumes the value of a hug. Physical contact (among people of the same gender) is highly acceptable in Albania and Kosovo. However, it is unacceptable in certain circumstances which are determined by the status, religious faith, and traditions of the interlocutors.

It is worth noting that practicing religion was prohibited for several decades in Albania during the Communist dictatorship of Albanian dictator Enver Hoxha and his associates from 1945-1990. Only after the fall of the Communist regime and the restoration of religious institutions, some fading elements of nonverbal communication reappeared, that is among relatively small social groups, Muslim Albanian women who wore the hijab for instance.

Kosovo, which was part of Communist Yugoslavia after WWII, did not go through the same religious repression as in Albania. (Kosovo Albanians suffered severe repression on political and ethnic grounds, though.)

Kosovo has been an independent and sovereign country since February 2008. Kosovo and Albania have communicated freely at all levels, as political entities, in economic, educational, cultural, as well as personal aspects since 1999, when Kosovo won freedom.

\section{Eye Contact}

As they say, eyes are the mirror of the soul. Eye contact is a crucial part of nonverbal communication. Eye contact can express emotions, attitudes, intentions, etc. When the sender and the receiver of the information have interest in communication with each other, they can express it with eye contact, amongst other ways of doing it. Extending eye contact can be positive (e.g. conveying sympathy, noting the significance of the topic being discussed, or the importance of the interlocutor) or negative (establishing dominance, threats, or challenges). Furthermore, eye contact can be used to express doubt, approval, or rejection. Specific signals conveyed by eye contact are distinguished by the time span, the direction of the eyes, and the frequency of eye contact. ${ }^{2}$

\footnotetext{
2 „Die Dauer des Blickkontakts kann eine positive (Übertragung von Sympathie, Wichtigkeit der Nachricht, Wichtigkeit des Gesprächspartners o.ä.) oder eine negative Bedeutung haben (z.B. Dominanz, Bedrohung, Herausforderung) bzw. fragend, zustimmend oder ablehnend sein. Die einzelnen Blicksignale unterscheiden sich hauptsachlich durch deren Richtung, Dauer und Blickhäufigkeit." (Argyle, 2005, p.66)

Our translation: "The duration of the eye contact can be positive (transfer of sympathy, importance of the message, importance of the conversation partner, etc.) or negative meaning (e.g. dominance, threat, challenge) or questioning, approving or rejecting. The individual gaze signals differ mainly in their direction, duration and frequency of gaze."
} 
Eye contact regulates conversation and signals the exchange of speaker and listener roles. It occurs between $10-30 \%$ of the conversation. Eye contact is used to acknowledge or avoid the presence of others and can reveal information about attitudes, emotion, dominance and power in social relationships. When there are breakdowns in conversation it may be because the people conversing have different patterns of eye contact (which can be a result of differing cultural backgrounds). When individuals respond with their eyes they allow others to have a sense of their emotional state and can increase feelings of communication satisfaction (Webbink, 1986).

Albanians seek and maintain eye contact with their interlocutors. This extended interest in maintaining eye contact is considered annoying by Germans. On the other hand, Albanians consider the lack of an extended eye contact as disinterest by their interlocutors and a sign of disrespect. Often, due to differences in how the two cultures perceive eye contact, Germans feel as excessively observed and consider this as a type of aggressive behavior towards them. A reason for this difference could be the long isolation of Albania, and to a degree of Kosovo, and the lack of contact with other cultures.

In Albania, Kosovo, and Germany, two persons look at each other on the eyes when they converse, and this is considered as appropriate.

Quick eye contact, also known as „look-and away“, is seen as an attempt to avoid staring (see Fast, 2002, p.124). Quick eye contact is present during unusual situations, to minimize or avoid excessive staring. For instance, this happens when one sees a man with a birthmark, a woman with revealing clothes, etc. In other words, one watches at them only „briefly“.

Direct eye contact is usual and even necessary in Albania and Kosovo. Not to look at someone in the eye is perceived as showing no interest in the interlocutor, or no sincerity towards him/her.

Perhaps from this behavior, Albanians in both Albania and Kosovo use the expression 'Ai, që nuk të sheh në sy, ka prapamendim' ('The one who doesn't look you in the eye, has a design upon you'). In the south of Albania, this expression is replaced by a determinative 'siultë' (an amalgamation of the words 'sy' (eye) and 'ulët' (down).

It should be noted that, in Albania and Kosovo, lowering one's own eyes is perceived as a signal of submission and admittance of guilt. In certain cases, lowered eyes accompanied by a head-nod can be interpreted as approval.

\section{Facial Expression}

When discussing nonverbal signals, it is important to discuss facial expressions as the face has the potential to convey accurately a wide variety of signals. The most important nonverbal channel for expressing attitudes and emotions to other people is the face (Argyle, 1988). Researchers have attempted to categorize facial expressions that express emotion and typically agree on six: happiness, surprise, fear, sadness, anger, disgust/contempt. 
(Ekman, 1982 cited by Argyle, 1988). Face expressions are used by people in three different fields:

Für die nonverbalen Signale ist das Gesicht der wichtigste Bereich des Körpers, denn es hat eine hohe Ausdruckskraft und kann deswegen Informationen besonders gut senden. Der Gesichtsausdruck findet beim Menschen in drei ganz unterschiedlichen Bereichen Anwendung (Argyle, 2005, p.202) ${ }^{3}$

a) Personal features are characteristic as a model of a person's reaction. People are distinguished based on their faces because their mimicry expresses part of their personality;

b) Emotions are expressed through a model which is developed gradually. These emotions are modified and controlled by social rules, but partially they are controlled by cognitive factors as well;

c) The aim of mimicry is to fulfill and support the signals of interaction, which are conveyed through mimicry, such as raising eyebrows.

The first aspect depends more on physical structures, while the second is determined by the autonomous system of nerves, and the third by the central one. Personality is distinct in all these three fields.

The face is the most vivid part of our body. One often judges strangers based on their facial expressions. Facial expressions are quite complicated and they depend on the culture in which one is brought up. However, there are certain feelings whose corresponding facial expressions are universally manifested, such as: envy, hatred, condolences, happiness, fear, surprise, dismay, interest, etc.

That we laugh and cry and express our feelings using mimicry is natural. But when and how to do it depends on the culture in which we have been raised. Culture determines the expression of feelings, disciplines and shapes them. ${ }^{4}$

Albanians are generally considered expressive, as they tend to openly express their feelings. Thus, Albanian interlocutors immediately distinguish the interlocutor's emotional state based on his/her face expressions. Our field work in different geographical areas populated by Albanians has made us conclude that one can ask for directions and understand them even if one does not speak or understand Albanian. This is due to the lively facial expressions accompanied by body language. This is applicable in the University environment as well. The lecturer can easily infer how a student feels when

\footnotetext{
3 Our translation: The face is the most important area of the body for the non-verbal signals, because it has a high expressiveness and can therefore send information particularly well. The facial expression is used in humans in three very different areas. (Argyle, 2005, p.202)

4 "Dass wir lachen und weinen und Gefühle mimisch ausdrücken, liegt in der Natur des Menschen. Aber wann und wie wir das tun, ist abhängig von der Kultur, in der wir aufgewachsen sind. Sie prägt die Gefühlsausdrücke, diszipliniert und überformt sie." (Wahrlich, 2002, p.4)

Our translation: "It is human nature that we laugh and cry and express emotions. But when and how we do that depends on the culture in which we grew up. It shapes the expressions of feeling, disciplines and transforms them." (Wahrlich, 2002, p.4)
} 
he/she observes the student's charisma. Students 'facial expressions are simple to be interpreted and they help the lecturer to understand if the students have understood what is being lectured to them. If the lecturer wants students to remain silent or to speak up, then it is sufficient for the lecturer to signal his/her students using his/her own facial expressions. Smiling is an automatic feature among Albanians, and at the same time it is a sign of respect.

\section{Body Language}

Body language often supports the signals that the face conveys. Body language consists of gestures, movement of hands, fingers or arms, posture, etc. Body language depends on both the culture and the individual. Some gestures which are considered appropriate in one place, are unacceptable or taboo in other places, or they simply disappear completely.

Albanians gesticulate a lot. The Mediterranean influence could explain this. Very often, Albanians use the expression '...flet me duar e me këmbë' ('he/she speaks with hands and legs', meaning that one is very expressive, or gesticulates a lot). This indicates that gesticulation is part and parcel of the Albanian tradition.

Albanians accompany their speech with gestures and this helps them express their thoughts and feelings easily. In the majority of the cases, they cannot help gesticulating when they talk, using this to clarify their expressions.

This way, for instance, nodding one's head vertically is interpreted as either approval or rejection in different parts of Albania. Historically, a vertical nod is interpreted as a refusal in Albania. By the end of the $20^{\text {th }}$ century, this has changed due to the contacts with other cultures. Therefore, new generations interpret vertical nods as approval, while older generations see them as rejection.

Horizontal nodding, on the other hand, is interpreted as approval. However, as with the vertical nodding, young people have changed their interpretation of horizontal nodding to mean negation or refusal. Meanwhile, in Kosovo moving the head horizontally has always been interpreted as negation, and it is used when the two people conversing do not agree with one another.

It is usual that Albanians in Albania and Kosovo move their hands and fingers to support a verbal claim. Everyday gestures, the usage of the index finger are very usual in Kosovo and Albania. The results of our intensive field work in the past five years has made us conclude that this gesture in some cities might not be considered very appropriate.

In Albania and Kosovo, in the majority of the cases, gestures are used to support what is being said, and to convey one's interpersonal position. Friends and acquaintances gesticulate more when talking to one another rather than when talking to strangers. The latter case is evident in a person's posture (mien).

\section{Physical Appearance}


Physical appearance has a powerful impact. It shows how we treat ourselves and the others. Many people are less attractive than what the others think. Body image can be manipulated to look more attractive, threatening, happy, etc. A significant role is played by various aspects of physical appearance. One's choice of attire is not always made according to the weather conditions, but also to convey a statement for the person, his or her personality, social standing, etc.

Every day we choose how to shape our physical appearance either knowingly or unknowingly (for instance, when one applies cosmetic products, makes a choice between wearing a dress or pants, a particular shirt, their colors and other accessories we wear).

Every society has a dress code. Before an official meeting, we do think about our appearance. We know how to express grief via clothes or how to impress the others with shiny jewelry. If one does not want to follow the unwritten rules of clothing, he/she manages to transmit a clear message. Dress codes are different in different cultures, and often these differences are determined by the political system of a country.

The physical appearance of Albanians today is closely related to the history and development of the country after half a century of dictatorship. Before the fall of the Communist regime, Albania was an isolated place and its motto was that the country must build itself and be self-reliant rather than seek foreigners' help. In this context, in Albania all citizens were nominally treated the same regardless of who they were - in other words there was not enough room to express individuality. This can be illustrated even by the expressions of that time „Të ngrënët sipas qejfit, veshja sipas shokut"(roughly translated as „eating according to your taste, dressing according to your social class“). A separate identity was not supposed to be developed according to individual choices and preferences but it was determined by the Communist State. The regime saw it necessary that the worldviews of the youth be concomitant with the principles of the State and the Party. Uniformity of the state and the whole population was an everyday effort of that time. In Albania, the black school uniform and the red scarf were the uniform of the youth and they determined the desired identity. At times when the Communist political establishment was more orthodox, young people with long hair were forcefully given haircuts. Going to school wearing a t-shirt or jeans was taboo and considered as a „foreign, imperialist manifestation“. Designing and making clothes was regulated under the regime's economical views. There was a lack of funding for qualitative materials. This, of course, limited the choice of clothes people could wear. When a foreigner walked in town, it was obvious that they were foreigners not only by their choice of attire. While foreign clothes were wanted more, domestic products were considered cheaper and not fashionable. The dominant colors were dark. Colorful or white clothes were stereotypically foreign. Only after the fall of the regime, Albanians had the chance to choose their own clothes as they wished, and this often resulted in exaggeration and imitation of Western commercials.

While Albania was in strict isolation, Kosovo was part of the former Yugoslavia, which was also a communist country but with milder measures than Albania, as we have already 
noted. Kosovo Albanians who lived in towns did not differ much from their neighbors, while in rural areas traditional clothing dominated. Kosovo Albanians started wearing jeans and t-shirts much earlier than those in Albania.

Germans, foreigners generally, who have seen reality for themselves after the fall of the Communist regime in early 1990s, were frequently surprised at the attention-grabbing make-up and revealing clothes of women in offices in Albania. In Albania and Kosovo, it is usual that women wear elegantly and 'take care' of their physical appearance. In Germany, it is more important to feel comfortable.

For foreigners, sights of every-day life in Albania and Kosovo are unusual: female students and women wearing high heels, donning elegant dresses and excessive jewelry. Albanians pay a lot of attention to their appearance. Often, in Albania and Kosovo one can be judged based on what one chooses to wear. In Germany, this is highly unlikely.

\section{Paralinguistic Field}

The paralinguistic field is comprised of elements related to the voice. There are two basic elements: first, how we express our thoughts, the state of our voice, the strength of tonality, intonation, language melodicity, pauses, accent, etc. Second, nonverbal noises such as laughter, yawning, murmuring, etc. In writing, these paralinguistic elements are expressed by punctuation, typography, writing style, etc. Studies show that we transmit one third of messages through direct means of communication, i.e. through voice.

Paralinguistic communication is especially important in conversations over the phone or in radio broadcasts, due to the fact that these media transmit only the voice. One's position, emotions, personality traits and worldviews are transmitted through vocal signals. Albanians are in the habit of talking loudly to one another. Foreigners sometime perceive this behavior - mistakenly - as a contradiction or argumentation between the interlocutors. Perhaps this can be explained by the Albanians' temperament and their living conditions.

\section{RESULTS, DISCUSSIONS AND SUGGESTIONS}

In summary, it can be said that it is not easy to correctly interpret non-verbal signs because the individual signs are communicated consciously or unconsciously, emphasize or refute what is spoken, and are individual or culturally shaped. This can lead to misinterpretations, especially in an intercultural communication situation.

Han (2004, p.86-87) draws attention to the fact that nonverbal signs of other cultures, which are conventional there and have a clear meaning, cannot have the same sign meaning but may have a completely different meaning in another culture. It is important to know and understand cultural taboos. Several measures can be taken to achieve this goal. On the one hand, social skills of the interaction partners must be trained. The primary goals are to become aware of intercultural nonverbal differences and to understand that any misunderstandings cannot always be derived from the language 
skills or even the personality of the other person. Because a correct handling of interculturality can only be understood and learned through theory and practice.

The following quote from Wylie (1977) demonstrates that in addition to learning a language system, nonverbal communication is also important to learn and understand:

"[...] Traditional language learning, dominated by a preoccupation with words, syntax, and pronunciation, has all but ignored these other channels of communication. No wonder language students complain that they do not really learn to interact with other people. "(Wylie 1977, p.vii)

As a result, it is not enough for successful communication to understand the other person's language. In the same way, it should also be possible to decode the nonverbal communication channels and distance mechanisms.

The findings of our research and field work, which we have elaborated in this article, indicate that non-verbal communication is an important part of communication in the contexts of Albanian and German speaking areas, including in the area of language acquisition for Albanian-speaking students of German. Intercultural communication varies not only between nations (Albania versus Germany, for instance) but also amongst people of the same nation living in different socio-political environments for long, existing as two separate countries now (Albania, Kosovo).

Further analysis in the field of nonverbal communication is important, especially now in the digital era, and an ever-increasing flow of people globally, and contacts between Albanian-speaking and German speaking people after the fall of the Berlin Wall and Communism in Albania and Kosovo. An interesting line of investiogation will be the way increased contacts between Albanians and Germans in the past 30 years have impacted nonverbal communication amongst them.

\section{References}

Andersen, P. A., Hecht, M. L., Hoobler, G. D., \& Smallwood, M. (2002). Nonverbal communication across cultures. In W. B. Gundykunst \& B. Moody (Eds.), Handbook of International and Intercultural Communication. Thousand Oaks, CA: Sage.

Argyle, M. (1988). Bodily Communication, 2nd ed. New York, NY: Methuen.

Argyle, M. (2005). Körpersprache und Kommunikation: Das Handbuch zur nonverbalen Kommunikation. Paderborn: Junfermann Verlag.

Edward T. Hall's interpersonal distances of man. (n.d.) Rerieved January 30, 2020, from Wikipedia Interact website: https://en.wikipedia.org/wiki/Proxemics\#/media/File:Personal Space.svg .

Erll, A. \& Gymnich, M. (2007). Interkulturelle Kompetenzen. Erfolgreich kommunizieren zwischen den Kulturen. Stuttgard: Klett-Verlag.

Fast, J. (2002). Body Language. Revised and Updated. New York: M. Evans and Co.

Hall, E. (1976). Die Sprache des Raumes. Düsseldorf: Pädagogischer Verlag Schwann.

Hall, E. T. (1959). The Silent Language. Garden City, NY: Doubleday.

Hall, E. T. (1976). Beyond Culture. Garden City, NY: Doubleday. 
Han, S. G. (2004). Ausdrucksformen und Funktionen nonverbaler Kommunikation in interkulturellen Begegnungssituationen. Eine empirische Analyse deutsch-koreanischer Kommunikation. In: Europäische Hochschulzeitschriften. Series XL Kommunikationswissenschaft und Publizistik - Vol. 87. Frankfurt am Main: Peter Lang GmbH. pp. 19 - 87.

Harris, T. E. (2002). Applied Organizational Communication: Principles and Pragmatics for Future Practice. Mahwah, NJ: LawrenceErlbaum Association.

Knapp, M. L., \& Hall, J. A. (2002). Nonverbal Communication in Human Interaction. Crawfordsville, IN: Thomson Learning.

Oksaar, E. (1988). Kulturemtheorie. Ein Beitrag zur Sprachverwendungsforschung. Hamburg: Joachim-Jungius-Gesellschaft der Wissenschaften.

Richmond, V. P., \& McCroskey, J. C. (2004). Nonverbal Behavior in Interpersonal Relations. Boston, MA: Allyn and Bacon/Pearson Education.

Sommer, R. (1979). Personal space. Englewood Cliffs: Prentice-Hall.

Ting-Toomey, S. (1999). Communicating Across Cultures. New York: The Guilford Press.

Vargas, M. (1986). Louder than words. Ames, IA: Iowa State University Press.

Watzlawick, P.\& Beavin, J. M. \& Jackson, D. D. (1967). Pragmatics of human communication. New York: W. W. Norton \& Company.

Webbink, P. (1986). The Power of Eyes. New York: Springer Publishing.

WEB1, Edward T. Hall's interpersonal distances of man. (n.d.) Retrieved from Wikipedia Interact website: https://en.wikipedia.org/wiki/Proxemics\#/media/File:Personal Space.svg

Wylie, L. (1977). A Guide to French Body Talk. Cambridge, Massachusetts. New York: The Undergraduate Press, Dutton. 